\title{
PENGARUH BIG DATA DAN TEKNOLOGI BLOCKCHAIN TERHADAP MODEL BISNIS SEKTOR LOGISTIK DENGAN PENDEKATAN BUSINESS MODEL CANVAS
}

\author{
Sutandi \\ Program Studi Manajemen Logistik Institut STIAMI \\ Email : sutandi@stiami.ac.id, sutankindi@gmail.com
}

\begin{tabular}{|c|c|}
\hline ARTICLE INFO & ABSTRACT \\
\hline $\begin{array}{l}\text { Keywords: } \\
\text { Big Data, } \\
\text { Blockchain, } \\
\text { Business Model Canvas } \\
\text { (BMC), } \\
\text { Logistik }\end{array}$ & $\begin{array}{l}\text { Dunia saat ini sedang menuju era digitalisasi dan otomasi. Hal ini menjadi kunci utama } \\
\text { dalam strategi persaingan bisnis, tidak terkecuali di sektor logistik. Salah satu elemen } \\
\text { yang digunakan dalam digitalisasi dan otomasi adalah penggunaan data untuk } \\
\text { pengambilan keputusan organisasi. Teknologi Big Data dan Blockchain saat ini mulai } \\
\text { dipergunakan oleh berbagai sektor bisnis dalam meningkatkan kemampuan usaha suatu } \\
\text { organisasi dengan menciptakan proses bisnis yang efisien. Tentunya hal ini akan } \\
\text { berpengaruh terhadap model bisnis yang baru yaitu transformasi baru yang fit terhadap } \\
\text { perkembangan dunia bisnis. Dalam menganalisis perubahan baik secara internal dan } \\
\text { ekternal digambarkan dengan business model canvas (BMC). Analisis SWOT terhadap } \\
\text { perubahan model bisnis diperlukan untuk mengelaborasi perubahan proses bisnis yang } \\
\text { baru. Berdasarkan analisa didapatkan hasil bahwa; pertama, kemajuan teknologi saat } \\
\text { ini khususnya Big Data dan Blockhain akan terus mendistrupsi bisnis untuk } \\
\text { meningkatkan kinerja yang optimal. Kedua, penerapan Big Data dan Blockchain } \\
\text { memperlihatkan bahwa terjadi perubahan baik secara internal maupun ekternal terkait } \\
\text { dengan relasi intra dan antar organisasi. Ketiga, analisis SWOT dapat mengelaborasi } \\
\text { keunggulan teknologi Big Data dan Blockchain dalam sektor bisnis khusunya di bidang } \\
\text { logistik. }\end{array}$ \\
\hline
\end{tabular}

\section{PENDAHULUAN}

1. Latar belakang

Dunia saat ini sedang menuju era digitalisasi dan otomasi. Hal ini menjadi kunci utama dalam strategi persaingan bisnis, tidak terkecuali di sektor logistik. Salah satu elemen yang digunakan dalam digitalisasi dan otomasi adalah penggunaan data untuk pengambilan keputusan organisasi.

Tantangan pertama yang dihadapi saat ini adalah bagaimana mengelola data yang sangat banyak dan komplek agar dapat optimal dimanfaatkan oleh perusahaan. Karakteristik data yang sangat banyak dipengaruhi oleh perkembangan teknologi informasi yang terkoneksi dengan internet seperti smartphone, CCTV, RFID, dan sebagainya. Tingkat kompleksitas data juga sangat beragam mulai dari teks, gambar, suara, dan video, merupakan suatu tantangan dalam mengelolanya. 
Konsep Big Data adalah terkait dengan 3Vs yaitu Volume, Velocity dan Variety. Oleh karena itu, perusahaan harus memanfaatkan 3 hal tersebut untuk meningkatkan kemampuan usaha suatu organisasi dengan menciptakan proses bisnis yang efisien, menangani pelanggan dan pada akhirnya menciptakan model bisnis baru yang fit terhadap perkembangan dunia bisnis.

Tantangan kedua adalah bagaimana sistem kerja antar bagian di dalam perusahaan ataupun antar perusahaan menjadi lebih efektif. Saat ini berbagai pihak yang terlibat dalam bisnis setuju bahwa ketika memiliki banyak informasi dapat mendorong hasil yang lebih baik. Saat ini sedang berkembang teknologi Blockchain, dengan Blockchain, setiap proses/gerakan dipecah menjadi blok, dan transaksi didokumentasikan setiap kali berpindah tangan. Dengan mengaitkan blok bersama-sama, semua orang dapat melihat siapa yang terlibat dalam proses dan dapat menelusuri detail spesifiknya. Hal itu menciptakan sejarah digital permanen saat produk bergerak di seluruh rantai pasok dari awal hingga akhir. Tujuannya adalah untuk menciptakan satu versi kebenaran, menghubungkan informasi, menciptakan transparansi seputar semua pihak yang terlibat dalam rantai pasok, dan mengidentifikasi bagaimana mereka berpartisipasi dalam arus barang atau jasa. Teknologi ini tidak dimiliki atau dikontrol oleh salah satu mitra dagang, hal ini tersedia untuk semua mitra.

Tidak dapat dipungkiri bahwa Big Data dan teknologi Blockchain mempengaruhi sektor logistik saat ini. Walmart berencana untuk menggunakan teknologi Blockchain untuk melacak pergerakan produk makanan. IBM dan Maersk mengumumkan bahwa mereka berkolaborasi untuk menggunakan teknologi Blockchain. Dengan menggunakan Blockchain, 3PL dan shippers dapat menambah nilai dari rantai pasok. Data yang dihasilkan teknologi Blockchain dapat menyediakan peluang dalam menganalisa informasi, dimana hal ini menjadi penting saat ini. Karena Blockchain dapat melacak dengan teliti dan menyediakan transparasi, retailer dapat memonitor persediaan. Hal ini dapat mengubah rantai pasok menjadi dinamis. Studi menemukan bahwa 3PL dan shipper sedang pada tahap awal untuk mengimplementasikan teknologi Blockchain, dan karena hal ini baru tahap awal, ekosistem Blockchain butuh pengembangan lebih lanjut. Tentunya hal ini akan mengubah cara kerja model bisnis yang ada menjadi suatu model bisnis yang baru.

\section{Tujuan Penelitian}

Penelitian ini bertujuan untuk mengetahui faktor-faktor yang berpengaruh terhadap perubahan model bisnis di sektor logistik baik secara internal maupun eksternal dengan pendekatan business model canvas. Selanjutnya diharapkan dengan menganalisa bisnis model yang baru dapat memberikan pemahaman yang baik, dan akan dikembangkan penelitan lanjutan terhadap model bisnis yang baru ini.

3. Manfaat penelitian

Secara akademis, penelitian ini diharapkan dapat membantu menjabarkan lebih jelas mengenai perubahan model bisnis yang terjadi saat ini dan yang akan datang. Sehingga diharapkan dapat 
menyediakan referensi baru tentang pengaruh Big Data dan Blockchain terhadap business model canvas (khususnya dibidang logistik).

Secara praktis, penelitian ini diharapkan memberi manfaat melalui analisis yang dipaparkan pada dunia usaha untuk dapat beradaptasi dengan perubahan teknologi dan bagi pembuat kebijakan untuk menformulasikan kebijakan dengan tepat sasaran.

4. Penelitian terdahulu

\section{Big Data}

Big Data adalah teknologi baru untuk mengelola, menganalisis, dan memvisualisasikan data yang berkembang pesat yang dihadapi dalam perusahaan dan masyarakat (Bollier, 2010; Bryant et al., 2008; Brown et al., 2011). Big Data Analytics (BDA) mengacu pada teknologi dan kerangka kerja yang dirancang untuk dengan cepat menyimpan, mengkonversi, mentransfer, dan menganalisis sejumlah besar data yang terus diperbarui, langsung bervariasi, terstruktur dan tidak terstruktur untuk keuntungan komersial dan sosial (Russom, 2011). BDA kini telah berevolusi dari sistem manajemen basis data besar ke layanan cloud untuk memproses dan menganalisis data untuk membuatnya lebih ekonomis, lebih efektif, dan lebih mudah bagi pengguna untuk memanipulasi (Baer, 2011; Borkar et al., 2012). Perusahaan vendor utama data global antara lain IBM, Oracle, SAP, EMC, Teradata, dan SAS. Solusi yang saat ini ditawarkan oleh vendor ini meliputi Gudang Data, Penambangan Data, Analisis Bisnis, Intelijen Bisnis, Data Visualisasi, Pendukung Keputusan, Antarmuka Otomasi, dan sejenisnya.

Big Data memiliki tiga fitur: volume, kecepatan, dan variasi (Russom, 2011). Sebagian besar diskusi di masa lalu berfokus pada cara menyimpan volume data. Kecepatan dan variasi sangat penting dalam diferensiasi kompetitif. Ragam mengacu pada berbagai format data. Data dapat berupa data terstruktur yang dapat diurutkan atau data non-terstruktur, seperti gambar, musik, video, esai, dan diskusi. Dibandingkan dengan data terstruktur, data non-terstruktur memberikan refleksi yang lebih baik dari kenyataan untuk membuat keputusan penting (Adrian, 2012; Cohen et al., 2009). Fitur lainnya adalah kecepatan. Dalam lingkungan bisnis di mana setiap hitungan detik, bisnis harus mengumpulkan dan menganalisis data secara tepat waktu untuk membuat keputusan penting lebih cepat dibandingkan dengan pesaing mereka. Dengan memproses volume besar informasi yang terus berubah yang harus diproses segera, bisnis dapat mengubah massa data yang tampaknya tidak berguna menjadi nilai ekonomi (McAfee dan Brynjolfsson, 2012).

\section{Blockchain}

Blockchain adalah buku digital yang didistribusikan transaksi yang tidak dapat digunakan dengan karena penggunaan metode kriptografi (Pilkington 2016). Penjelasan singkat ini mencakup tiga properti terpenting dari Blockchain: de-sentralisasi, terverifikasi, dan tidak dapat diubah. (1) Ini 
terdesentralisasi karena jaringan sepenuhnya dijalankan oleh anggotanya, tanpa bergantung pada otoritas pusat atau infrastruktur terpusat yang membangun kepercayaan. Untuk menambahkan transaksi ke buku besar, transaksi harus dibagikan dalam jaringan peer-to-peer Blockchain. Semua anggota menyimpan salinan buku besar lokal mereka sendiri. (2) Hal ini diverifikasi karena anggota menandatangani transaksi menggunakan kriptografi publik-privat-kunci sebelum membaginya dengan jaringan. Oleh karena itu, hanya pemilik kunci privat yang dapat memulainya. Namun, anggota dapat tetap anonim karena kunci tidak terkait dengan identitas dunia nyata. (3) Tidak dapat diubah melalui algoritme konsensus: Satu transaksi atau lebih dikelompokkan bersama untuk membentuk blok baru. Semua anggota jaringan dapat memverifikasi transaksi di blok. Jika tidak ada konsensus tentang validitas blok baru tercapai, blok ditolak. Sama halnya, jika konsensus ada bahwa transaksi dalam blok itu valid, blok tersebut ditambahkan ke rantai. Hash cryptographic dihasilkan untuk setiap blok. Setiap blok tidak hanya menyimpan catatan transaksi tetapi juga hash dari blok sebelumnya. Ini menciptakan interdependensi blok yang menghubungkan ke rantai - Blockchain. Mengubah transaksi pada Blockchain secara retroaktif tidak hanya akan mengubah catatan lokal di sebagian besar perangkat anggota jaringan, tetapi juga mengubah kumpulan kriptografis dari setiap blok di rantai.

Sistem terdistribusi, seperti Blockchain, menyimpan manfaat dibandingkan arsitektur terpusat karena menyediakan informasi yang sama dan terverifikasi kepada semua anggota jaringan. Ini menciptakan kepercayaan di antara para pihak dengan menghilangkan kebutuhan akan kepercayaan. Blockchain dapat mencatat transfer aset antara dua pihak, tanpa membutuhkan perantara yang tepercaya. Aset semacam itu dapat berupa uang digital, tetapi juga kredit karbon atau akta kepemilikan lainnya (Tapscott \& Tapscott 2016).

\section{Business Model Canvas (BMC)}

Sejarah dari Model Bisnis Kanvas, berasal dari disertasi PhD yang dimulai pada tahun 2000 dan sebagai Business Model Canvas. Pengguna menempatkan Canvas untuk bekerja di area yang sangat berbeda dari organisasi mereka. Mayoritas pengguna yang disurvei menerapkan Bisnis Model Kanvas ke mengembangkan bisnis yang sepenuhnya baru, meluncurkan produk dan layanan baru, atau mengubah yang sudah ada model bisnis dan strategi. Model Bisnis Kanvas juga banyak digunakan oleh para akademisi. Sekolah bisnis berperingkat teratas di seluruh dunia seperti Stanford, Harvard atau IESE mengadopsi Model Bisnis Kanvas di ruang kelas mereka. Siswa belajar bagaimana menerapkan Canvas di strategi dan inovasi dalam program MBA dan Eksekutif terkemuka, dan mereka membawa ini pengetahuan mutakhir kembali ke organisasi mereka. Semakin banyak pengguna yang menerapkan Model Bisnis Kanvas untuk menggambarkan strategi saat ini dan masa depan

Business Model Canvas terdiri dari sembilan komponen dasar model bisnis. Komponen tersebut diletakkan di atas kanvas sehingga visualisasi hubungan isu-isu yang berbeda diperbaiki. Itu membantu pengguna untuk memetakan, mendiskusikan, merancang, dan menciptakan model bisnis 
baru. Semuanya pada dasarnya dapat dibagi dalam produk di sisi kiri dan pasar di sebelah kanan, sedangkan proposisi nilai jelas dibagi menjadi setengah.

Di sebelah kanan kami memiliki 'Segmen Pelanggan', semua orang atau organisasi yang akan menciptakan nilai, termasuk pengguna dan pelanggan. Untuk setiap segmen, kami memiliki 'Proposisi Nilai' tertentu, semua bundel produk dan layanan yang menciptakan nilai bagi pelanggan. 'Saluran' menjelaskan interaksi dengan pelanggan dan memberikan nilai, sementara 'Hubungan Pelanggan' menguraikan jenis hubungan yang dibuat dengan pelanggan. Menutup bagian kanan kanvas, 'Aliran Penghasilan' menjelaskan bagaimana dan melalui mekanisme penetapan harga.

Aset yang sangat diperlukan dari bisnis yaitu ditampilkan di 'Sumber Daya Utama' di sebelah kiri langsung di bawah 'Kegiatan Utama', hal-hal yang perlu dilakukan dengan baik. 'Mitra Utama' adalah mereka yang membantu dalam memanfaatkan model bisnis, karena tidak akan memiliki semua sumber daya kunci atau melakukan semua kegiatan utama sendiri. Dan dengan memahami infrastruktur bisnis dengan BMC, maka akan mendapatkan gagasan tentang 'Struktur Biaya'.

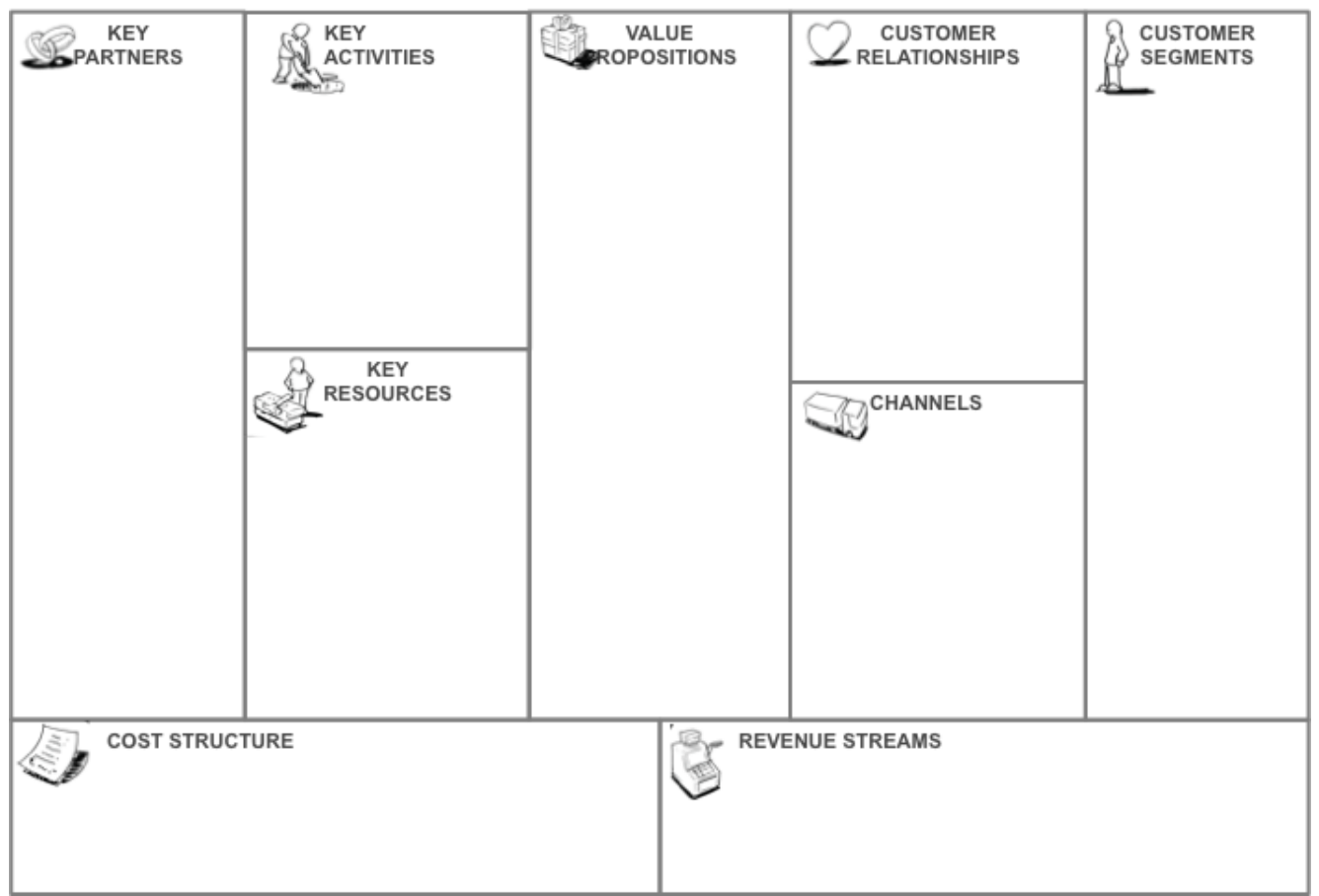

Gambar 1. Business Model Canvas (BMC)

\section{METODOLOGI}

Peneliti akan mengidentifikasi perubahan sistem kerja pada internal dan ekternal yang terdapat pada business model canvas (BMC) untuk mengetahui pengaruh dari penggunaan Big Data dan Blockchain. Setelah mengidentifikasi perubahan sistem kerja internal dan eksternal BMC, peneliti akan menganalisa dengan menggunakan SWOT khususnya untuk sektor logitsik. Analisis SWOT bertujuan mengidentifikasi kekuatan dan kelemahan suatu organisasi serta kemampuan mengatasi perubahan yang terjadi dalam lingkungan bisnis (Johnson dan Scholes (1994) (dalam Kalpande, dkk (2010)). SWOT membantu untuk mengevaluasi model bisnis perusahaan. 


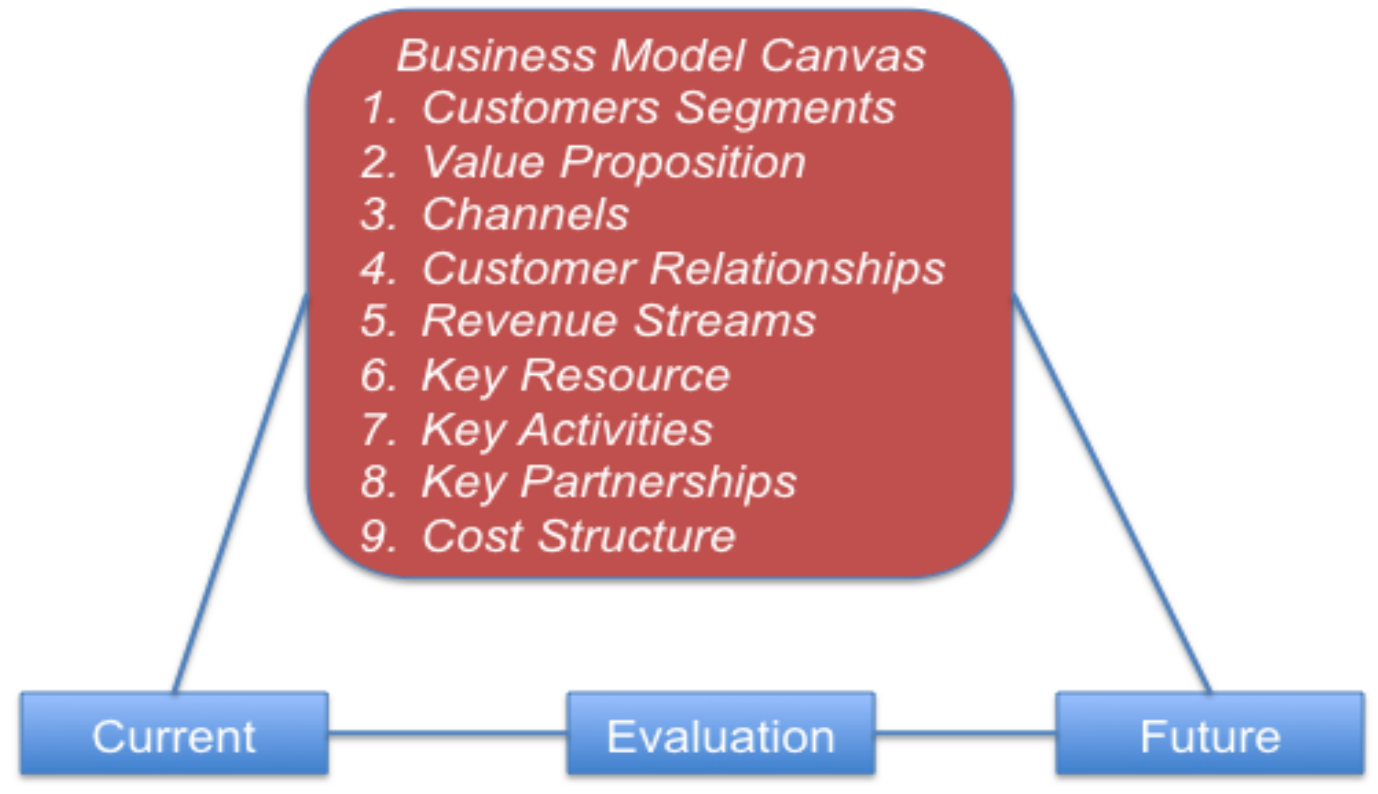

Gambar 2.Kerangka Penelitian

Sumber: Osterwalder dan Pigneur (2009)

\section{Jenis Penelitian}

Jenis penelitian yang digunakan adalah penelitian kualitatif deskriptif di mana penelitian ini berupaya mengumpulkan data, menganalisis secara kritis atas data-data tersebut dan menyimpulkannya berdasarkan fakta-fakta pada masa penelitian (Sugiama, 2008).

\section{Subjek dan Objek Penelitian}

Subjek penelitian di sini yaitu proses kerja BMC. Dalam penelitian ini, objek penelitian adalah business model canvas yang dipengaruhi oleh Big Data dan Teknologi Blockchain.

\section{Sumber Data}

Sumber data berasal dari data sekunder. Dalam penelitian ini, buku, jurnal dan data internet akan digunakan sebagai sumber data sekunder.

\section{HASIL DAN PEMBAHASAN}

Dalam penerapan Blockchain prinsip utama adalah perubahan dari sistem sentralisasi menjadi sistem terdistribusi. Pendekatan sentralisasi, keuntungannya terutama terletak dalam hal kontrol. Perusahaan bisa mengontrol informasi dan pesan yang harus disampaikan kepada pelanggan. Keuntungan lain adalah kolaborasi dengan departemen atau divisi lain menjadi lebih mudah. Kelemahan dengan struktur sentralisasi adalah besarnya resources yang diperlukan untuk membangun infrastruktur yang lengkap karena harus membangun mulai dari nol. Kelemahan lain yang dominan adalah proses yang lambat dalam merespons perubahan. Dan ini jelas tidak sesuai dengan perubahan teknologi digital yang cenderung sangat cepat. Konsep ini tunjukan pada Gambar 1. 
Sebaliknya, dengan pendekatan terdistribusi, perusahaan kehilangan kemampuan untuk mengontrol informasi dan konten. Di sisi lain, alternatif ini menawarkan berbagai keuntungan yang menjadi kelemahan sentralisasi. Pertama, setiap entitas memiliki wewenang dan kebebasan untuk mengembangkan banyak hal. Struktur ini juga sudah pasti akan lebih sesuai bila perusahaan ingin meningkatkan respons terhadap perubahan di pasar. Konsep distribusi Blockchain juga dapat diartikan sebagai suatu sistem yang dimana keseluruhan pengambilan keputusan diserahkan kepada para pengguna sistem tersebut dan tidak adanya salah satu individu yang dapat memaksakan kehendaknya kepada individu lain tanpa persetujuan mayoritas pengguna sistem.
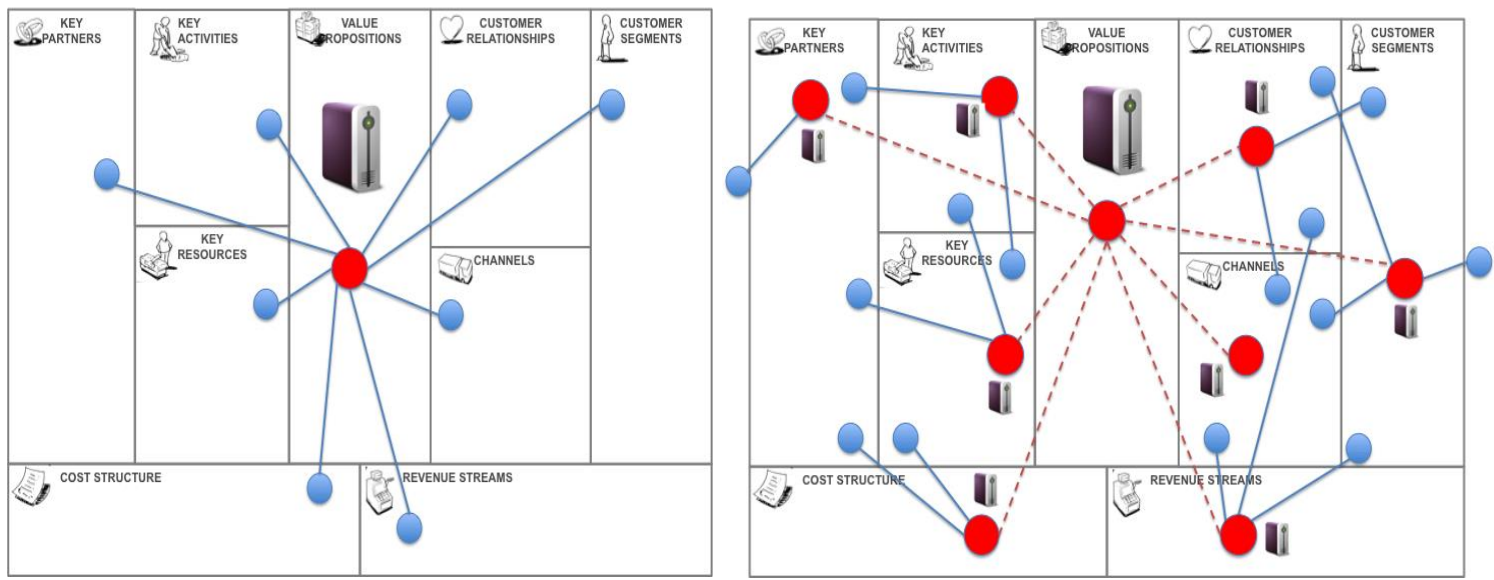

Gambar 1. Konsep Sentralisasi dan Desentralisasi dalam Internal BMC

Perubahan cara kerja dalam BMC secara internal terjadi akibat dari pengaruh dari penggunaaan teknologi Big Data dan Blockchain. Big Data akan menggunakan penyimpanan secara tersentralisasi dengan bantuan teknologi cloud, sedangkan penggunaaan Blockchain akan meningkatkan visibilitas dari setiap bagian dalam unit usaha terkait share informasi. Hal ini ditunjukan pada Gambar 2.

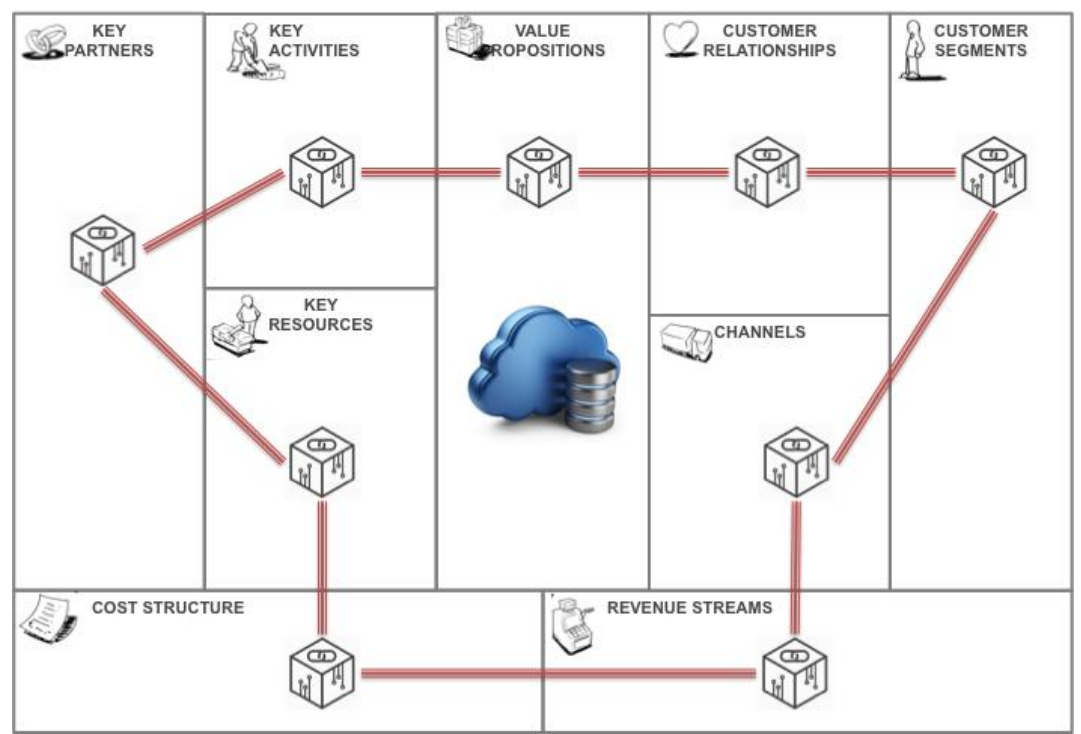

Gambar 2. Big Data dan Blockchain Mempengaruhi Cara Kerja Internal BMC 
Hubungan antar organisasi masa kini dicirikan oleh kesalingtergantungan (interde-pendensi) satu sama lain karena situasi lingkungan yang dinamis dan terus berubah. Perubahan atau pergeseran dari sifat independen ke interdependen telah melahirkan berbagai pemikiran yang mengarahkan kepada model pengelolaan bisnis berdasarkan kemitraan, tidak lagi berdasarkan kompetisi (persaingan). Oleh karena itu, kolaborasi sangat dibutuhkan saat ini. Teknologi Big Data dan Blockchain mendukung antar perusahaan untuk dapat berkolaborasi dengan baik dalam hal kemampuan menggunakan dan berbagi data.

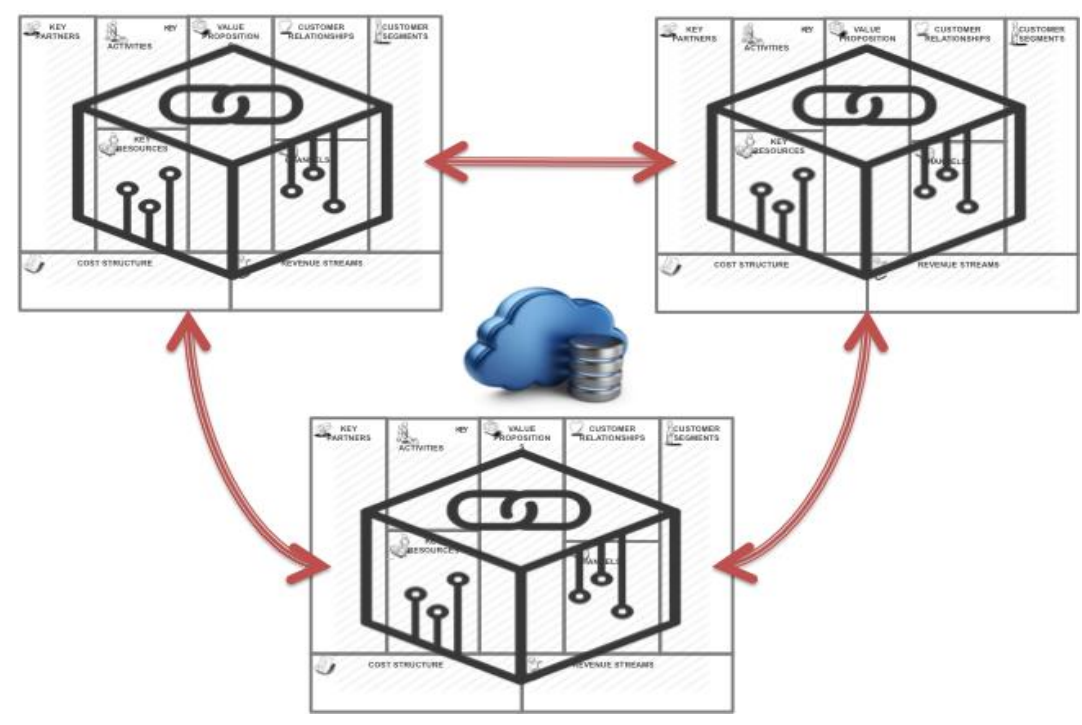

Gambar 3. Big Data dan Blockchain Mempengaruhi BMC Antar Perusahaan

Penerapan teknologi Big Data dan Blockchain dalam sektor logistik pada gambar 4 dibawah akan berdampak antara lain (1) akses yang cepat dan aman ke informasi rantai pasokan end-to-end, satu sumber kebenaran; (2) keaslian dan keabsahan dokumen digital yang dapat diverifikasi; (3) alur kerja lintas-organisasi tepercaya; (4) penilaian risiko yang lebih baik dan lebih sedikit intervensi; (5) biaya administrasi jauh lebih rendah dan dihilangnya biaya untuk memindahkan kertas fisik melintasi batas internasional.

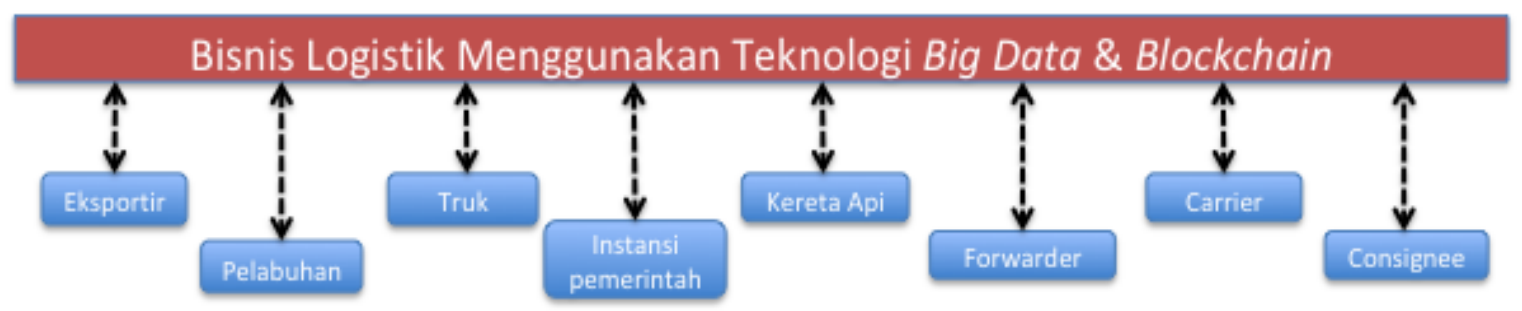

Gambar 4. Penerapan Big Data dan Blockchain Pada Bisnis Logistik

\section{SWOT untuk Big Data}

Kekuatan:

- Membantu dunia bisnis dalam melakukan analisa, perhitungan statistik, dan Business Intelegent. 
- Menerapkan alat analitik dengan teknologi yang tersedia saat ini (RFID, GPS, ...), yang semakin murah dan murah, akan memungkinkan pengumpulan wawasan dan informasi tentang logistik dan operasi secara real-time. Ini berarti bereaksi lebih cepat dan lebih cepat terhadap masalah.

Kelemahan:

- Kurangnya teknologi untuk mendukung semua format, implementasi saat ini memiliki logika yang kompleks.

- Banyak data tidak terstruktur hadir di platform seperti - media sosial.

Peluang:

- Peluang besar untuk memproses data besar seperti audio, video, dan gambar.

- Ketrampilan analitik harus dikembangkan untuk memecahkan penghalang antara jumlah data yang demikian dan informasi yang berarti untuk suatu bisnis tertentu. Data yang tidak dapat diakses samasama tidak berguna dan informasi yang terlewatkan.

- Peluang untuk pengecer online, perusahaan penyimpanan, perusahaan jaringan, perusahaan produk perangkat lunak, industri kesehatan, dan perusahaan jasa.

- Pendekatan rantai pasokan berbasis permintaan mungkin diperluas dengan berbagi lebih banyak data dengan mitra utama dan dengan mengumpulkan wawasan dari pasar: dari pelanggan serta pelanggan pelanggan dan dengan demikian mengantisipasi tren dan inovasi daripada bergantung terutama pada prakiraan tidak dapat diandalkan.

Ancaman:

- Prediksi yang salah karena data sampah seperti dalam kasus analisis sosial, tidak dapat memprediksi pola pikir manusia.

- Terganggu oleh inovasi lain. Inilah yang mungkin terjadi setiap kali model bisnis baru, lebih dekat dengan kebutuhan pelanggan (atau yang menciptakan kebutuhan baru), diciptakan berkat inovasi TI.

- Model bisnis baru menciptakan Jaringan pemasok baru.

\section{SWOT untuk Blockchain}

\section{Kekuatan}

- Tidak Ada Jaringan Terpusat: Aspek terpenting dari Blockchain yang menjadikannya solusi keamanan IoT yang sesuai adalah jaringan terdesentralisasi. Untuk memvalidasi perubahan dalam blok, semua sistem di jaringan (setidaknya 50\%) perlu memverifikasi data.

- Ekosistem Tangguh: Karena teknologi bekerja dalam jaringan terdesentralisasi, tidak ada ruang untuk satu titik pun kegagalan..

- Database yang Dapat Diperpanjang: Tidak ada kekurangan database dalam model Blockchain.

- Karena Blockchain dapat melacak dan memverifikasi pergerakan seluruh tahapan produksi, pengiriman dan arus barang, hal ini dapat menghilangkan banyak resiko dalam proses perpindahan barang dalam rantai pasok. 
- Dalam tiap tahap, Blockchain akan mengidentifikasi pihak-pihak yang terlibat. Detail seperti harga, tanggal, lokasi, keadaan produk dan informasi lainnya dapat dilihat untuk mengetahui pengiriman tersebut. Ketersediaan buku besar/ledger dapat digunakan untuk melacak produk ke asal usul bahan baku yang digunakan. Data tersebut penting agar diupdate secara realtime sehingga mengurangi kegiatan rekonsiliasi masing-masing pihak yang terlibat dalam rantai pasok tersebut.

- Terlebih lagi struktur buku besar tersebut terdesentralisasi membuat tidak mungkin bagi salah satu pihak untuk memanipulasi data karena tidak ada pihak yang memegang kendali secara penuh terhadap data tersebut. Hal ini meningkatkan akuntabilitas dan keamanan data.

- Informasi yang dibagikan akan meningkatkan visibilitas dan meminimalkan potensi human error. Hal ini juga dapat mengurangi waktu kegiatan, menghilangkan biaya tambahan, meminimalkan kesalahan dan mengurangi korupsi. Peningkatan akuntabilitas data yang dikelola dalam Blockchain dapat digunakan untuk analisis data terkait rantai pasok.

- Ketika Blockchain dikelola sampai end-user, Blockchain dapat menciptakan rantai permintaan karena Blockchain dapat melacak serta mentransimisikan data secara cepat terkait konsumsi

- Salah satu manfaat terbesar bagi shippers adalah dengan teknologi Blockchain ini menjamin keamanan dan transparansi untuk pelanggan. Hal ini meminimalkan penipuan serta pengiriman menjadi tepat. Hal ini juga dapat membantu mengatasi kesalahan karena Blockchain dapat menghasilkan manajemen rantai pasok yang lebih efektif dan efisien.

Kelemahan

- Entitas dengan sumber daya yang sangat besar dan kekuatan komputasi yang luas dapat membahayakan data yang membutuhkan sumber daya pemrosesan yang besar.

- Tidak semua perangkat yang terhubung ke IoT memiliki kekuatan pemrosesan yang cukup untuk melakukan algoritma enkripsi tingkat tinggi.

- Ditambah lagi ada biaya serta harus ada pihak yang bertanggung jawab dalam mengintegrasikan data tersebut. Beberapa pihak dapat menjadi sangat tertutup terkait sharing informasi tapi integrasi itu sangat penting dan bermanfaat

- Karena Blockchain membuat data terpusat yang dapat diakses oleh pihak-pihak terkait, diperlukan interoperabilitas di antara kebutuhan pribadi dan umum, sehingga diperlukan suatu aturan yang mengaturnya.

- Seiring dengan permasalahan terkait skalabilitas dan kurangnya protokol, privasi adalah salah satu permasalahan yang harus ditangani oleh teknologi Blockchain. Dalam beberapa kondisi mungkin perusahaan tidak ingin memberikan transparansi penuh atas semua informasi kepada pihak-pihak dalam rantai pasok.

- Kewajiban juga bisa menjadi hal yang perlu diperhatikan. Semakin banyak informasi dalam rantai pasok, maka semakin banyak hal yang dapat dipertanggungjawabkan. Dengan hal ini perusahaan dapat menentukan bahwa tidak menginginkan tingkat tracking yang rinci dan detail. 
- Selain itu, teknologi Blockchain sendiri tidak membahas keandalan terhadap catatannya. Seringkali orang yang bertindak sebagai pihak ketiga tepercaya mencatat informasi di Blockchain. Dalam kasus pelacakan atau praktik bisnis tidak etis lainnya, seorang individu dapat dengan mudah masuk ke dalam sistem Blockchain bahwa bisnis itu sah dan pelaku upstream dapat tertipu

- Terlebih lagi, Blockchain memerlukan verifikasi data pihak ketiga yang dimana hal ini memerlukan biaya tambahan.

Peluang

- Komunikasi Aman antara Perangkat IoT: Teknologi Blockchain membuat supply chain lebih terintegrasi. Hal ini merupakan potensi dalam mengubah cara kerja/proses rantai pasok namun pengaplikasiannya tidak sederhana.

Ancaman

- Masalah Perpajakan: Meskipun ada banyak manfaat dari Blockchain dalam ekosistem IOT, itu tidak akan mudah dan cepat untuk sepenuhnya menerapkan teknologi. Misalnya, ada masalah hukum yang perlu dijaga sebelum aplikasi lintas batas teknologi.

\section{KESIMPULAN}

Dengan penerapan BMC dan analisi SWOT dapat disimpulkan sebagai berikut; Pertama, kemajuan teknologi saat ini khususnya Big Data dan blockhain akan terus mendistrupsi bisnis untuk meningkatkan kinerja yang optimal. Kedua, penerapan Big Data dan Blockchain memperlihatkan bahwa terjadi perubahan baik secara internal maupun ekternal terkait dengan relasi intra dan antar organisasi. Ketiga, analisis SWOT dapat mengelaborasi keunggulan teknologi Big Data Big Data dan Blockchain dalam sektor bisnis khusunya di bidang logistik.

\section{DAFTAR PUSTAKA}

Adrian, M. (2012). Who's Who in NoSQL DBMSs. Gartner Report, G00228114. Afuah, A. and Tucci, C. L. (2001). Internet Business Models and Strategies: Text and Cases. Boston: McGraw-Hill.

Agrawal, D., Das, S., \& Abbadi, A. (2011). Big Data and Cloud Computing: Current State and Future Opportunities. ACM EDBT Conference, March 22-24, 2011, Uppsala, Sweden. http://dx.doi.org/10.1145/1951365.1951432

Baer, T. (2011). 2012 Trends to Watch: Big Data. Ovum Report, OI00140-041.

Borkar, V., Carey, M., \& Li, C. (2012). Inside "Big Data management”: Ogres, onions, or parfaits? ACM EDBT/ICDT Joint Conference, Berlin, Germany.

Ching, H. Y., and Fauvel, C. (2013). "Criticisms, variations and experiences with business model canvas", European Journal of Agriculture and Forestry Research Vol.1. No.2, pp. 26 -37, December 2013 
Cohen, J., Dolan, B., Dunlap, M., Hellerstein, J., \& Welton, C. (2009). MAD Skills: New analysis practices for Big Data. ACM VLDB conference, August 24-28, 2009, Lyon, France.

Kalpande, S.D., Gupta, G.C., Dandekar, M.D. (2010). A SWOT Analysis of Small and Medium Scale Enterprises Implementing Total Quality Management. International Journal of Business, Management and Social Sciences, 1(1), 59-64.

Kline, W. A., Hixson, C. A., Mason, T. W., Brackin, P., Bunch, R. M., Dee, K. C., Rose, G. and Livesay, G. A. (2013). "The Innovation Canvas - A Tool to Develop Integrated Product Designs and Business Models". 120th ASEE Annual Conference and Exposition, June 2013.

McAfee, A., and Brynjolfsson, E. (2012). Big Data: The management revolution.

Moleong, Lexy J. (2012). Metodologi Penelitian Kualitatif. Bandung: PT Remaja Rosdakarya.

Osterwalder, A. and Pigneur, Y (2010). Business Model Generation: John Wiley, NJ. "Why and How Organizations Around the World Apply the Business Model Canvas".

Osterwalder, A. dan Pigneur, Y. (2009). Business model generation: A handbook for visionaries, game changers, and challengers. Self published.

Pekuri, A. (2015). "The Role Of Business Models nn Construction Business Management, University of Oulu Graduate School”. University of Oulu, Faculty of Technology, Acta Univ. Oul. C 527, 2015

Petre, M. (2003). "Disciplines of innovation in engineering design. In N. Cross and E. Edmonds (eds) Expertise in Design”. Design Thinking Research Symposium 6. University of Technology, Sydney, Australia. .

Pilkington, M. (2016). "Blockchain Technology: Principles and Applications". In: Research Handbook on Digital Transformations. Ed. by F. X. Olleros and M. Zhegu. Edward Elgar Publishing, pp. 1-39.

Porter, M. E. (1991) Towards dynamic theory of strategy. Strategic Management Journal, 12, 95-117.

Russom, P. (2011). Big Data Analytics. TDWI Research, 4th Quarter, 2011.

Sugiama, A. Gima. (2008). Metode Riset Bisnis dan Manajemen. Bandung : Guardaya Intimarta.

Tapscott, D. and A. Tapscott (2016). Blockchain Revolution. 1st ed. New York: Penguin Random House. 